\title{
Atypical phenotypic aspects of autoimmune thyroid disorders in young patients with Turner syndrome
}

\author{
Tommaso Aversa, Romina Gallizzi, Giuseppina Salzano, Giuseppina Zirilli, Filippo De Luca* and Mariella Valenzise
}

\begin{abstract}
Aim of this commentary is to analyze the current views about the phenotypic features of Hashimoto's thyroiditis (HT) and Graves' disease (GD) in Turner syndrome (TS) girls, in terms of epidemiology, clinical and biochemical presentation, long-term course and metamorphic autoimmunity evolution. In TS GD course is not atypical, whereas HT course is characterized by both a mild presenting picture and a severe long-term evolution of thyroid function tests. Furthermore, TS girls seem to have an increased risk of switching over time from HT to GD. On the light of these findings, it may be concluded that TS girls with HT need a careful monitoring of thyroid status over time. Conclusions: 1) In children the association with TS is able to condition a peculiar phenotypic expression of HT in terms of epidemiology, presentation course and long-term metamorphic autoimmunity; 2) by contrast, children with TS do not exhibit an atypical clinical and biochemical course of GD, but only a significantly higher prevalence of this disease.
\end{abstract}

Keywords: Graves' disease, Hashimoto's thyroiditis, Metamorphic autoimmunity, Natural history, Thyroid status

\section{Background}

Turner syndrome (TS) is one of the most common chromosomopathies, with a reported prevalence of 1:2500 live-born females [1]. Individuals with TS have an increased risk for celiac disease and autoimmune thyroid disorders (AITDs), but also for type 1 diabetes, vitiligo and juvenile idiopathic arthritis [2,3]. Hashimoto's thyroiditis (HT) is, by far, the most common autoimmune disease in TS girls [2,4], whilst the association between this syndrome and Graves' disease (GD) has been reported to be significantly more infrequent [5-7].

The reasons for predilection of the thyroid gland as a target of autoimmunity in patients with TS have not been clearly identified to date [8], but this predilection might be simply explained, at least partially, on the basis of the close association between thyroid autoimmunity and female gender [5].

A very interesting aspect, which emerges from the analysis of the most recent reports on the relationships between TS and AITDs, is that the association with TS seems to be able to affect the phenotypic expression of

\footnotetext{
* Correspondence: filippo.deluca@unime.it

Department of Human Pathology in Adulthood and Childhood, University of Messina, Via Consolare Valeria, 98124 Messina, Italy
}

AITDs in pediatric age, with significant repercussions on their presentation and long-term course.

Aim of this commentary is to analyze the current views about the phenotypic features of TS-related AITDs in terms of epidemiology, clinical and biochemical presentation, long-term course and metamorphic autoimmunity evolution.

\section{Epidemiology and pathophysiology of AITDs in TS girls}

If compared with girls without TS, young patients with TS are distinctly more incline to develop AITDs. In fact, the prevalence of both HT and GD was reported to be significantly higher in TS girls than in the pediatric general population: respectively $10-20 \%[2,5,8,9]$ vs around $1.2 \%$ [10] for HT and $1.7-3 \%[5,6]$ vs $1.07 \%$ [11] for GD.

The increased susceptibility of TS girls to AITDs might be due to haploinsufficiency of the genes in the pseudoautosomal region of $\mathrm{X}$-chromosome $[3,12]$, which are known to be possibly involved in the immunoregulation process [12]. Another mechanism that has been postulated to be, at least partially, responsible for the increased susceptibility of TS girls to AITDs is an up-regulation of proinflammatory cytokines [13]. Finally, a decrease in the 
CD4: CD8 lymphocytic ratio, that has been observed in TS children, may play a key-role in conditioning the predisposition of these girls to autoimmunity.

Whatever the mechanism of the enhanced susceptibility of TS girls to AITDs, it may be argued, however, that these patients are, per se, more exposed to this risk, irrespective of familial predisposition, or association with other autoimmune disorders. In fact, it was reported that the frequency of family HT antecedents in a cohort of TS patients with HT may be significantly lower than that detected on a control pediatric population and that the association with other autoimmune extra-thyroidal disorders may not be more common than in controls [14].

Finally, it has to be emphasized that the majority of studies did not report any significant relationships between AITDs and a specific karyotype in TS individuals $[4,7,15]$, which may suggest that these patients are more prone to develop AITDs irrespectively of karyotype. Nevertheless, other authors had previously reported that AITDs may be more common in TS patients with X-isochromosome karyotype $[5,16]$. Therefore, this last point cannot be considered completely clarified.

\section{Presentation and evolution of GD}

The available studies aiming to investigate the course of GD in TS patients are sparse and based on scarce populations $[5-8,12]$. According to the results of the most recent one, it is possible to infer that GD in TS individuals presents later than in the pediatric general population [7], which is not surprising considering that the frequency of TS-related AITDs has been reported to increase with age and to double from the first to the third decade of life [2].

The clinical picture at presentation is not atypical, being characterized by the same manifestations that are generally observed in GD children without TS: goiter, tachycardia, weight loss and other hyperthyroid symptoms [7]. Nevertheless, ophthalmopathy has been reported to be initially very infrequent and FT4 serum levels, at the time of diagnosis, have been found to be lower than those detected in GD children without TS [7]. Both these findings seem to indicate that diagnosis of hyperthyroidism in TS may be probably assessed in an earlier phase, since these girls, at the time of GD onset, are already under special control and have regular consultations with endocrinologists [7].

Also the subsequent clinical course of GD does not seem to be different in the patients with TS than in those without TS [7]. In fact, the initial remission rates after the start of methimazole treatment, the relapse rates after the first methimazole treatment cycle withdrawal, the prolonged remission rates after a 2-year withdrawal of pharmacological therapy and even definitive remission rates were found to be very similar in the two groups with or without TS [7]. It has also to be underlined that the initial methimazole doses and those needed to maintain euthyroidism were not different in the two groups. Finally, even the rates of girls who need a non-pharmacological treatment do not seem to be significantly higher in GD girls with TS [7].

\section{Presentation and evolution of HT}

According to the results of the first study aiming to compare the presentation biochemical patterns of HT in two groups of children with or without TS [14], HT presents with a less severe hormonal picture in TS girls. In fact, the girls with TS exhibited, at the time of HT diagnosis, a significantly higher prevalence of euthyroidism and a lower prevalence of both overt hypothyroidism and hyperthyroidism, whereas the prevalence of subclinical hypothyroidism $(\mathrm{SH})$ was very similar in the two cohorts (Fig. 1). Moreover, at entry, TS patients showed lower median TSH levels, when compared to those without TS [14].

The less severe biochemical pattern of thyroid function that was initially found in TS series might be explained on the light of a less aggressive autoimmune pattern, as also suggested by the significantly lower thyroid autoantibody levels which were detected, at HT diagnosis, in TS girls [14]. Another possible explanation is that several pediatricians are aware that TS girls have a more elevated risk of developing AITDs and, therefore, may be on the alert, even in presence of minimal symptoms.

By contrast, the evolution of thyroid status over time in girls with TS is characterized by a severe deterioration of thyroid tests, during a 5-year follow-up, in an elevated percentage of patients (Fig. 2).

Therefore, it is possible to argue that the association with TS is able to impair the long-term prognosis of thyroid function in girls with HT. Such a negative effect is more evident in the TS patients presenting with SH [14, 17], but may be observed even in initially euthyroid girls [18]. Furthermore, this effect is not necessarily linked with a specific karyotype [18].

\section{Metamorphic thyroid autoimmunity}

HT and GD are caused by two distinct and separate paradigms [16] and were regarded for a long time as two different entities. Nevertheless, more recent views have taken into consideration the hypothesis that these conditions might be two ends of the AITD spectrum [19]. In fact, it has been sporadically reported that GD and HT may follow one another in the same individuals [19], due to a sequential phenotypic conversion from HT to GD [20-22], or vice versa [23]. The most common metamorphic scenario concerns the progression from GD into HT, whilst the metamorphosis from HT into GD seems to be less common $[19,20]$. 


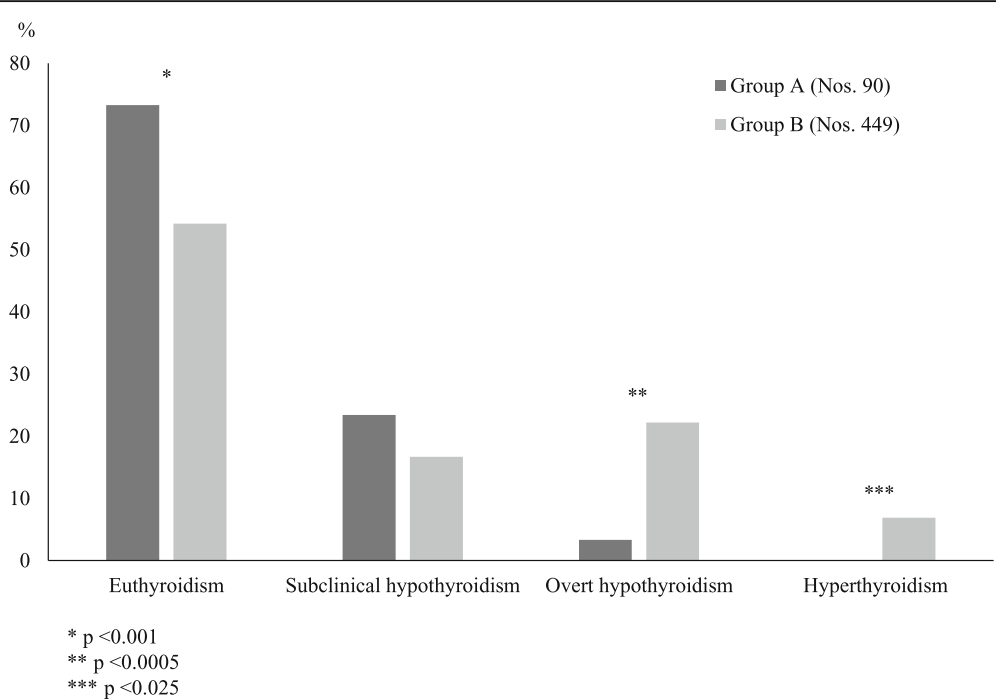

Fig. 1 Prevalences (\%) of the main biochemical pictures of thyroid function detected, at diagnosis of Hashimoto's thyroiditis (HT), in two groups of HT girls with (Group A) or without (Group B) Turner syndrome (according to the results of Reference [14] study)

Among the variables that have been postulated to be able to affect the shifting process from HT into GD, a predisposing role has been recently ascribed to the association with either TS or Down's syndrome (DS) $[19,24]$. In fact, patients with either TS or DS and associated HT were found to be at higher risk of progressing toward GD [24].

\section{Follow-up and management of TS girls with AITDs}

GD generally presents with a severe clinical and biochemical picture in both patients with or without TS and a therapeutic intervention is, therefore, needed in all cases. By contrast, HT presentation in children and adolescents without TS may be very various $[25,26]$ and treatment has to be necessarily and immediately started only in the cases presenting with overt hypothyroidism [27, 28].

In the girls with TS, the natural course of HT is more severe than in those without TS, being frequently characterized by a significant deterioration of thyroid status over time [14, 17-19]. Therefore, it may be inferred that these girls should require continued monitoring of thyroid function from 4 years of age onward [29], as also suggested by the TS Study Group Consensus in 2007 [30]. According to the statements of the last and very recent guidelines of the International TS Study Group Consensus, it is recommended to screen for thyroid dysfunctions all the girls at diagnosis of TS. Subsequently, all these patients should undergo annual measurements of FT4 and TSH from early childhood and throughout life-span [31].

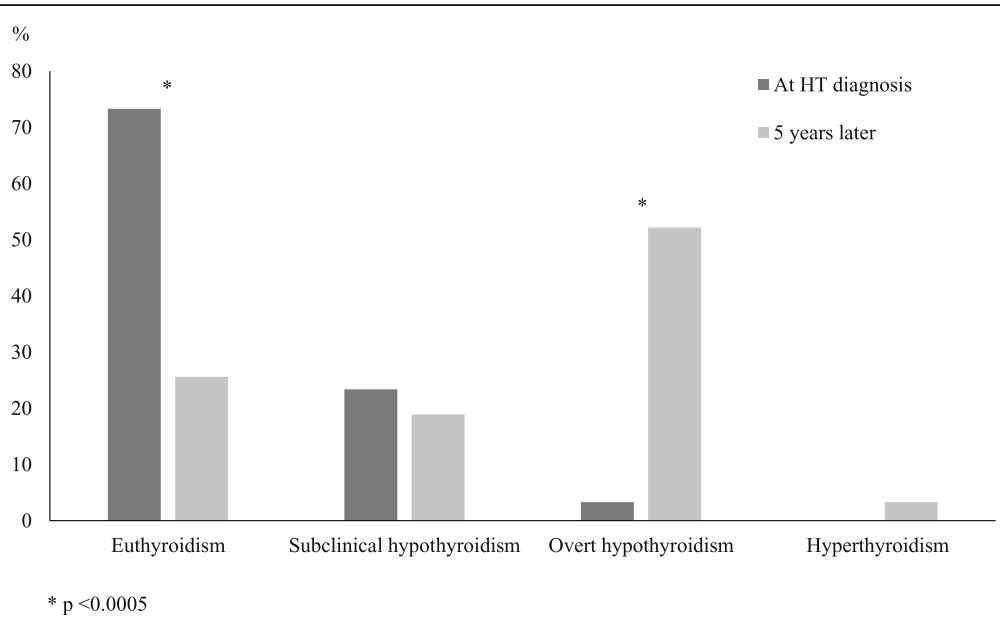

Fig. 2 Prevalences (\%) of the main biochemical pictures of thyroid function detected in 90 girls with Turner syndrome and associated Hashimoto's thyroiditis $(\mathrm{HT})$, at the time of $\mathrm{HT}$ diagnosis and 5 years later (according to the results of Reference [14] study) 
Anti-thyroid autoantibody measurement is recommended at diagnosis of HT or at the first detection of thyroid enlargement. Thyroid ultrasonography is not always necessary for HT diagnosis [31].

\section{Conclusions}

1) In children, the association with TS is able to condition a peculiar phenotypic expression of HT in terms of epidemiology, presentation course and longterm metamorphic autoimmunity; 2) by contrast, children with TS do not exhibit an atypical clinical and biochemical course of GD, but only a significantly higher prevalence of this disease.

\section{Abbreviations \\ AITDs: Autoimmune thyroid disorders; DS: Down syndrome; GD: Graves' disease; HT: Hashimoto's thyroiditis; SH: Subclinical hypothyroidism; TS: Turner syndrome}

\section{Acknowledgements}

Not applicable.

\section{Funding}

This research did not receive any specific grant from any funding agency in the public, commercial or not-for-profit sector.

\section{Availability of data and materials}

Not applicable.

\section{Authors' contributions}

TA and MV have written the paper; RG and FDL have organized the material and prepared its distribution in the different sections; GS and GZ have collected references and prepared graphics. Each Author listed on the manuscript has seen and approved the submission of the present version of the manuscript and takes full responsibility for the manuscript.

\section{Ethics approval and consent to participate}

Not applicable.

\section{Consent for publication}

Not applicable.

\section{Competing interests}

The authors declare that they have no competing interests.

\section{Publisher's Note}

Springer Nature remains neutral with regard to jurisdictional claims in published maps and institutional affiliations.

Received: 15 December 2017 Accepted: 3 January 2018

Published online: 17 January 2018

\section{References}

1. Lleo A, Moroni L, Caliari L, Invernizzi P. Autoimmunity and Turner's syndrome. Autoimmun Rev. 2012;11:A538-43.

2. Larizza D, Calcaterra V, Martinetti M. Autoimmune stigmata in Turner syndrome: when lacks an X chromosome. J Autoimmun. 2009;33:25-30

3. Jørgensen KT, Rostgaard K, Bache I, Biggar RJ, Nielsen NM, Tommerup N, Frisch M. Autoimmune diseases in women with Turner's syndrome. Arthritis Rheum. 2010;62:658-66.

4. Gawlik A, Gawlik T, Januszek-Trzciakowska A, Patel H, Malecka-Tendera E. Incidence and dynamics of thyroid dysfunction and thyroid autoimmunity in girls with Turner's syndrome: a long-term follow-up study. Horm Res Paediatr. 2011;76:314-20.

5. Livadas S, Xekouki P, Fouka F, Kanaka-Gantenbein C, Kaloumenou I, Mavrou A, et al. Prevalence of thyroid dysfunction in Turner's syndrome: a long-term follow-up study and brief literature review. Thyroid. 2005;15:1061-6.

6. Wasniewska M, Corrias A, Messina MF, Crisafulli G, Salzano G, Valenzise M, et al. Graves' disease prevalence in a young population with Turner syndrome. J Endocrinol Investig. 2010;33:69-70.

7. Valenzise M, Aversa T, Corrias A, Mazzanti L, Cappa M, Ubertini G, et al. Epidemiology, presentation and long-term evolution of Graves' disease in children, adolescents and young adults with Turner syndrome. Horm Res Paediatr. 2014;81:245-50.

8. Fukuda I, Hizuka N, Kurimoto M, Morita J, Tanaka S, Yamakado Y, et al. Autoimmune thyroid diseases in 65 Japanese women with Turner syndrome. Endocr J. 2009;56:983-6.

9. Grossi A, Crinò A, Luciano R, Lombardo A, Cappa M, Fierabracci A. Endocrine autoimmunity in Turner syndrome. Ital J Pediatr. 2013:39:79.

10. Tozzoli R, Perini R. Malattie autoimmuni nei primi anni di vita: dai sintomi alla diagnosi di laboratorio. Ital J Lab Med. 2007;3:45-50.

11. Cooper GS, Stroehla BC. The epidemiology of autoimmune diseases. Autoimmun Rev. 2003;2:119-25.

12. Bakalov VK, Gutin L, Cheng CM, Zhou J, Sheth P, Shah K, et al. Autoimmune disorders in women with Turner syndrome and women with karyotypically normal primary ovarian insufficiency. J Autoimmun. 2012;38:315-21.

13. Gravholt CH, Hjerrild BE, Mosekilde L, Hansen TK, Rasmussen LM, Frystyk J, Flyvbjerg A, Christiansen JS. Body composition is distinctly altered in Turner syndrome: relations to glucose metabolism, circulating adipokines, and endothelial adhesion molecules. Eur J Endocrinol. 2006;155:583-92.

14. Aversa T, Messina MF, Mazzanti L, Salerno M, Mussa A, Faienza MF, et al. The association with Turner syndrome significantly affects the course of Hashimoto's thyroiditis in children, irrespective of karyotype. Endocrine. 2015;50:777-82.

15. El-Mansoury M, Bryman I, Berntorp K, Hanson C, Wilhelmsen L, LandinWilhelmsen K. Hypothyroidism is common in Turner syndrome: results of a five-year follow-up. J Clin Endocrinol Metab. 2005;90:2131-5.

16. Elsheikh M, Wass JA, Conway GS. Autoimmune thyroid syndrome in women with Turner's syndrome-the association with karyotype. Clin Endocrinol. 2001;55:223-6.

17. Wasniewska M, Aversa T, Salerno M, Corrias A, Messina MF, Mussa A, et al. Five-year prospective evaluation of thyroid function in girls with subclinical mild hypothyroidism of different etiology. Eur J Endocrinol. 2015;173:801-8

18. Wasniewska M, Salerno M, Corrias A, Mazzanti L, Matarazzo P, Corica D, et al The evolution of thyroid function after presenting with Hashimoto thyroiditis is different between initially Euthyroid girls with and those without turner syndrome. Horm Res Paediatr. 2016;86:403-9.

19. Aversa T, Valenzise M, Salerno M, Corrias A, lughetti L, Radetti G, et al. Metamorphic thyroid autoimmunity in Down syndrome: from Hashimoto's thyroiditis to Graves' disease and beyond. Ital J Pediatr. 2015;41:87.

20. Wasniewska M, Corrias A, Arrigo T, Lombardo F, Salerno M, Mussa A, et al. Frequency of Hashimoto's thyroiditis antecedents in the history of children and adolescents with graves' disease. Horm Res Paediatr. 2010;73:473-6.

21. Takasu N, Matsushita M. Changes of TSH-Stimulation Blocking Antibody (TSBAb) and Thyroid Stimulating Antibody (TSAb) over 10 years in 34 TSBAbpositive patients with hypothyroidism and in 98 TSAb-positive Graves' patients with hyperthyroidism: reevaluation of TSBAb and TSAb in TSH-receptorantibody (TRAb)-positive patients. J Thyroid Res. 2012;2012:182176.

22. Troisi A, Novati P, Sali L, Colzani M, Monti G, Cardillo C, et al. Graves' hyrotoxicosis following Hashimoto's thyroiditis. Res Rep Endocr Disord. 2013;3:13-5.

23. Umar H, Muallima N, Adam JM, Sanusi H. Hashimoto's thyroiditis following Graves' disease. Acta Med Indones. 2010;42:31-5.

24. Aversa T, Lombardo F, Corrias A, Salerno M, De Luca F, Wasniewska M. In young patients with Turner or Down syndrome, Graves' disease presentation is often preceded by Hashimoto's thyroiditis. Thyroid. 2014:24:744-7.

25. Wasniewska M, Corrias A, Salerno M, Lombardo F, Aversa T, Mussa A, et al. Outcomes of children with hashitoxicosis. Horm Res Paediatr. 2012:77:36-40.

26. De Luca F, Santucci S, Corica D, Pitrolo E, Romeo M, Aversa T. Hashimoto's thyroiditis in childhood: presentation modes and evolution over time. Ital J Pediatr. 2013;39:8

27. Wasniewska M, Corrias A, Aversa T, Valenzise M, Mussa A, De Martino L, et al. Comparative evaluation of therapy with $L$-thyroxine versus no treatment in children with idiopathic and mild subclinical hypothyroidism. Horm Res Paediatr. 2012;77:376-81. 
28. Aversa T, Valenzise M, Corrias A, Salerno M, De Luca F, Mussa A, et al. Underlying Hashimoto's thyroiditis negatively affects the evolution of subclinical hypothyroidism in children irrespective of other concomitant risk factors. Thyroid. 2015;25:183-7.

29. Valenzise M, Aversa T, Zirilli G, Salzano G, Corica D, Santucci S, et al. Analysis of the factors affecting the evolution over time of subclinical hypothyroidism in children. Ital J Pediatr. 2017;43:2.

30. Bondy CA. Turner syndrome study group. Care of girls and women with Turner syndrome: a guideline of the Turner syndrome study group. J Clin Endocrinol Metab. 2007;92:10-25.

31. Gravholt $\mathrm{CH}$, Andersen NH, Conway GS, Dekkers OM, Geffner ME, Klein KO, et al. Clinical practice guidelines for the care of girls and women with Turner syndrome: proceedings from the 2016 Cincinnati international Turner syndrome meeting. Eur J Endocrinol. 2017;177:G1-G70.

Submit your next manuscript to BioMed Central and we will help you at every step:

- We accept pre-submission inquiries

- Our selector tool helps you to find the most relevant journal

- We provide round the clock customer support

- Convenient online submission

- Thorough peer review

- Inclusion in PubMed and all major indexing services

- Maximum visibility for your research

Submit your manuscript at www.biomedcentral.com/submit
Biomed Central 